\title{
Effects of Farnesoid X Receptor Activation on Arachidonic Acid Metabolism, NF-kB Signaling, and Hepatic Inflammation ${ }^{\mathrm{S}}$
}

\author{
Zhibo Gai, Michele Visentin, Ting Gui, Lin Zhao, Wolfgang E. Thasler, Stephanie Häusler, \\ Ivan Hartling, Alessio Cremonesi, Christian Hiller, and Gerd A. Kullak-Ublick \\ Department of Clinical Pharmacology and Toxicology, University Hospital Zurich, University of Zurich, Zurich, Switzerland (Z.G., \\ M.V., S.H., C.H., G.A.K.-U.); Experiment Center, Shandong University of Traditional Chinese Medicine, Jinan, Shandong, China \\ (T.G.); Department of Endocrinology, Chinese PLA 309 Hospital, Peking, China (L.Z.); Department of General and Visceral \\ Surgery, Rotkreuzklinikum Munich, Munich, Germany (W.E.T.); Department of Clinical Chemistry and Biochemistry, University \\ Children's Hospital Zurich, Zurich, Switzerland (I.H., A.C.); and Mechanistic Safety, Novartis Global Drug Development, Basel, \\ Switzerland (G.A.K.-U.)
}

Received November 3, 2017; accepted May 7, 2018

\begin{abstract}
Inflammation has a recognized role in nonalcoholic fatty liver disease (NAFLD) progression. In the present work, we studied the effect of high-fat diet (HFD) on arachidonic acid metabolism in the liver and investigated the role of the farnesoid $X$ receptor (FXR, NR1H4) in eicosanoid biosynthetic pathways and nuclear factor $\kappa$ light-chain enhancer of activated B cells (NF-kB) signaling, major modulators of the inflammatory cascade. Mice were fed an HFD to induce NAFLD and then treated with the FXR ligand obeticholic acid (OCA). Histology and gene expression analyses were performed on liver tissue. Eicosanoid levels were measured from serum and urine samples. The molecular mechanism underlying the effect of FXR activation on arachidonic acid metabolism and NF-kB signaling was studied in human liver Huh7 cells and primary cultured hepatocytes. NAFLD was characterized by higher ( 25\%) proinflammatory
\end{abstract}

[leukotrienes $\left(\mathrm{LTB}_{4}\right)$ ] and lower ( 3-fold) anti-inflammatory [epoxyeicosatrienoic acids (EETs)] eicosanoid levels than in chow mice. OCA induced the expression of several hepatic cytochrome P450 (P450) epoxygenases, the enzymes responsible for EET synthesis, and mitigated HFD-induced hepatic injury. In vitro, induction of CYP450 epoxygenases was sufficient to inhibit NF-kB signaling and cell migration. The CYP450 epoxygenase pan-inhibitor gemfibrozil fully abolished the protective effect of OCA, indicating that OCA-mediated inhibition of NF-kB signaling was EET-dependent. In summary, NAFLD was characterized by an imbalance in arachidonate metabolism. FXR activation reprogramed arachidonate metabolism by inducing P450 epoxygenase expression and EET production. In vitro, FXR-mediated NF-kB inhibition required active P450 epoxygenases.

\section{Introduction}

Activation of the farnesoid X receptor (FXR, NR1H4), a transcription factor that regulates lipid and glucose metabolism in the liver, reduced hepatic inflammation and fibrosis in a mouse model of nonalcoholic fatty liver disease (NAFLD) (Zhang et al., 2009). Conversely, FXR deficiency caused increased hepatic inflammation and fibrosis (Sinal et al., 2000). FXR activation has been shown to repress nuclear factor $\kappa$ lightchain enhancer of activated B cells (NF-kB) activation and the production of proinflammatory cytokines and profibrotic factors

This work was supported by the Swiss National Science Foundation [Grant no. 310030_175639] to G.A.K.-U. and by the "Forschungskredit" of the University Zurich 2015 [Grant no. FK-15-037] to Z.G.

https://doi.org/10.1124/mol.117.111047.

S This article has supplemental material available at molpharm. aspetjournals.org. both in vivo and in vitro (Jiang et al., 2007; Miyazaki-Anzai et al., 2010; Hu et al., 2012; Gai et al., 2016).

Arachidonic acid breakdown and metabolism play a major role in triggering and resolving inflammation. Indeed, the balance between anti-inflammatory [epoxyeicosatrienoic acids (EETs)] and proinflammatory [leukotrienes (LTBs)] arachidonate metabolites is critical in many pathophysiological conditions (Needleman et al., 1986; Zeldin, 2001). Persistent leukotriene $\mathrm{B}_{4}\left(\mathrm{LTB}_{4}\right)$ production is a hallmark of chronic inflammatory diseases, including high-fat diet (HFD)-induced liver inflammation (Samuelsson et al., 1987; Tager and Luster, 2003; Subbarao et al., 2004; Chou et al., 2010; Spite et al., 2011; Li et al., 2015a). Conversely, high EET levels limit inflammation in cardiovascular disease and metabolic syndrome (Deng et al., 2010; Luria et al., 2011; Imig, 2012; Sodhi et al., 2012; Bettaieb et al., 2013).

EETs are generated from the epoxygenation of arachidonic acid by the cytochrome P450 (P450) epoxygenases (e.g., CYP2C,

ABBREVIATIONS: ALT, alanine aminotransferase; DHETs, dihydroxyeicosatrienoic acids; EETs, epoxyeicosatrienoic acids; EPHX2, epoxide hydrolase 2; FCS, fetal calf serum; GM, gemfibrozil; FXR, farnesoid X receptor; HFD, high-fat diet; LTBs, leukotrienes; NAFLD, nonalcoholic fatty liver disease; NASH, nonalcoholic steatohepatitis; NF-Kb, nuclear factor $\kappa$ light-chain enhancer of activated B cells; OCA, obeticholic acid; P450, cytochrome P450; UPLC-MS/MS, ultra-performance liquid chromatography -tandem spectrometry. 
CYP2J). P450 epoxygenase levels were decreased in the livers of patients with progressive stages of NAFLD, suggesting that P450 epoxygenase and EET levels might play a role in the progression of NAFLD (Fisher et al., 2009). We recently reported that FXR activation induced $\mathrm{P} 450$ epoxygenase mRNA expression levels in mouse kidney proximal tubular cells (Gai et al., 2016). In this work, we investigated the role of FXR in arachidonate metabolism and characterized the FXRP450-EET interaction in mice with HFD-induced NAFLD. Finally, we demonstrated in vitro that FXR-mediated NF-kB signaling repression is EET-dependent.

\section{Materials and Methods}

Animals. Female C57/BJ mice were randomly assigned to an HFD (D12331; Provimi Kliba, Kaiseraugst, Switzerland) or a chow diet (D12329; Provimi Kliba) for 16 weeks. In a separate experiment, after 8 weeks of an HFD, half of the obese mice were given obeticholic acid (OCA) mixed in the food ( $25 \mathrm{mg} / \mathrm{kg}$; Intercept Pharmaceuticals, New York, NY). Finally, mice were divided into three groups of six animals each: chow, HFD, and HFD-OCA. Liver from each animal was used for RNA, protein extraction, and histologic examination.

Enzyme and Metabolite Measurements. For 24-hour urine collection, metabolic cages were used. Urine and serum 14,15 dihydroxyeicosatrienoic acid (14,15-DHET) levels were measured by enzyme-linked immunosorbent assay (ab175811; Abcam, Cambridge, UK). Serum triglycerides, alanine aminotransferase (ALT), $\mathrm{LTB}_{4}$ levels, and 14,15-EET levels were measured with a triglyceride assay kit (ETGA-200, EnzyChrom), an ALT assay kit (ab105134; Abcam), a LTB $_{4}$ Parameter Assay Kit (KGE006B; R\&D Systems, Minneapolis, $\mathrm{MN}$ ), and a 14,15-EET enzyme-linked immunosorbent assay kit (DH2R; Detroit R\&D, Inc, Detroit, MI), respectively. EETs and LTB 4 levels in the culture medium were also assessed by ultra-performance liquid chromatography-tandem spectrometry (UPLC-MS/MS).

Sample Preparation for UPLC-MS/MS Metabolite Analysis. Five hundred microliters of cell culture medium was mixed with $300 \mu \mathrm{l}$ of methanol and $300 \mu \mathrm{l}$ of ultrapure water. Deuterated $\mathrm{LTB}_{4}$ and 14,15-EET ( $\mathrm{d}_{4}$-LTB4, $\mathrm{d}_{11}$-14,15-EET; Cayman Chemical, Ann Arbor, MI) were added as internal standards. The samples were incubated on ice and then centrifuged for 10 minutes at $1200 \mathrm{~g}$ at $4^{\circ} \mathrm{C}$. The supernatant was collected and diluted 3:1 with $1 \% \mathrm{NH}_{4} \mathrm{OH}$ and then loaded onto a mixed mode solidphase extraction column (Evolute Express AX; Biotage, Uppsala, Sweden). The columns were preconditioned with $1 \mathrm{ml}$ of methanol and $1 \mathrm{ml}$ of $1 \%$ $\mathrm{NH}_{4} \mathrm{OH}$. After sample loading, the column was washed with $2 \mathrm{ml}$ of $0.5 \mathrm{M}$ ammonium acetate/methanol (95:5) and $2 \mathrm{ml}$ of methanol. Analytes were eluted in $6 \mathrm{ml}$ of methanol/formic acid (98:2). The eluate was dried under nitrogen at $40^{\circ} \mathrm{C}$, reconstituted in $30 \%$ methanol, and injected into a UPLC-MS/MS system.

UPLC-MS/MS Analysis of Metabolites. The UPLC-MS/MS method was adapted and modified from Weiss et al. (2013). Analytes were separated on a CSH C18 column (Acquity UPLC CSH C18 $1.7 \mu \mathrm{m}$, $2.1 \times 150 \mathrm{~mm}$; Waters AG, Baden-Dättwil, Switzerland) thermostated at $35^{\circ} \mathrm{C}$ using an UPLC (Nexera $\times 2$; Shimadzu Schweiz GmbH, Reinach, Switzerland). Mobile phase A and B consisted of $0.125 \%$ $\mathrm{NH}_{4} \mathrm{OH}$ in double distilled water and methanol:acetonitrile (70:30), respectively. The following gradient was used: $\mathrm{T}_{0}, 35 \% \mathrm{~B} ; \mathrm{T}_{2}, 35 \% \mathrm{~B}$; $\mathrm{T}_{4}: 42 \% \mathrm{~B} ; \mathrm{T}_{5.5}: 44 \% \mathrm{~B} ; \mathrm{T}_{7}, 52 \% \mathrm{~B} ; \mathrm{T}_{10.5}, 52 \% ; \mathrm{T}_{14}, 70 \% \mathrm{~B}$. Mobile phase $\mathrm{B}$ was then increased to $90 \%$ for 2 minutes to clean the column before returning to starting conditions for 2 minutes. Analytes were detected using a Sciex Triple Quad 6500+ mass spectrometer (AB Sciex Switzerland GmbH, Baden, Switzerland) in negative-ion mode and scheduled multiple reaction monitoring. The optimized MS parameters were as follows: curtain gas $=35$, collision gas $=9$, ion spray voltage $=-4500 \mathrm{~V}$, temperature $=600^{\circ} \mathrm{C}$, ion source gas $1=70$, ion source gas $2=70$, declustering potential $=-40 \mathrm{~V}$, entrance potential $=-10 \mathrm{~V}$, cell exit potential $=-15 \mathrm{~V}$. The multiple reaction monitoring transitions used for quantification were $335.3 \rightarrow 195.2$ for $\mathrm{LTB}_{4}, 339.0 \rightarrow 197.0$ for $\mathrm{LTB}_{4}-\mathrm{d}_{4}, 319.1 \rightarrow 219.1$ for $14,15-\mathrm{EET}$, and $330.2 \rightarrow 219.1$ for $14,15-E E T-d_{11}$. The collision energy was optimized for each analyte as follows; $\mathrm{LTB}_{4}$ and $\mathrm{LTB}_{4}-\mathrm{d}_{4}=-22 \mathrm{~V}, 14,15-\mathrm{EET}=-16 \mathrm{~V}$, and 14,15-EET- $\mathrm{d}_{11}=-18 \mathrm{~V}$.

Liver Pathologic Assessments and Immunostaining. Livers were fixed overnight in formalin and embedded in paraffin. Threemicrometer sections were stained with H\&E and Masson's trichrome stains. The fibrotic areas were determined from Masson's trichromestained sections by digital images analyzed by an unbiased observer. Immunostaining was performed on paraffin sections using a microwave-based antigen-retrieval technique. The antibodies used in this study were against CD4 (sc-7219; Santa Cruz Biotechnology, Dallas, TX), aSMA (NBP1-30894; Novus Biologicals, Littleton, CO), and MAC387 (ab22506; Abcam). Sections were treated with the Envision $^{+}$DAB kit (Dako, Basel, Switzerland) according to the manufacturer's instructions.

For NAFLD score analysis, histopathologic damage was scored using the system proposed by the NASH Clinical Research Network. Three representative areas were scored in each section, and the average values were used as the final score.

Isolation of RNA from Liver Tissue and Cells and Quantification of Transcript Levels. Total RNA was prepared using standard Trizol extraction (Invitrogen, Waltham, MA). Two micrograms of total RNA was reverse-transcribed using random primers and Superscript II enzyme (Invitrogen, Carlsbad, CA). First-strand complementary DNA was used as the template for real-time polymerase chain reaction analysis with TaqMan master mix and primers (Applied Biosystems, Foster City, CA). Data were calculated and expressed relative to levels of RNA for the housekeeping gene hypoxanthine phosphoribosyltransferase or $\beta$-actin.

Microarray and Gene Expression Analysis. RNA was extracted from mouse liver using an RNeasy Microarray Tissue Mini Kit (73304; Qiagen, Hilden, Germany), followed by on-column DNase digestion to remove any contaminating genomic DNA. RNA samples from four mice per group were subjected to microarray analysis. Details on the analysis methods can be found at http://fgcz-bfabric. uzh.ch/wiki/tiki-index.php?page=app.two_groups. Gene ontology analysis, network analysis, and Kyoto Encyclopedia of Genes and Genomes pathway analysis of the microarray data were completed using the MetaCore online service (Thomson Reuters, Winter Park, FL; https://portal.genego.com/), and DAVID Bioinformatics Resources 6.8 (National Institute of Allergy and Infectious Diseases, National Institutes of Health; https://david.ncifcrf.gov/).

Cell Lines. Huh7 and THP-1 cells were maintained in RPMI 1640 medium supplemented with $10 \%$ fetal calf serum (FCS), $100 \mathrm{U} / \mathrm{ml}$ penicillin, $100 \mu \mathrm{g} / \mathrm{ml}$ streptomycin at $37^{\circ} \mathrm{C}$ in a humidified atmosphere of $5 \% \mathrm{CO}_{2}$. THP-1 cells were supplemented with $2 \mathrm{mM} \mathrm{L-}$ glutamine. J774 cells were grown in Dulbecco's modified Eagle's medium supplemented with $10 \% \mathrm{FCS}, 100 \mathrm{U} / \mathrm{ml}$ penicillin, and $100 \mu \mathrm{g} / \mathrm{ml}$ streptomycin at $37^{\circ} \mathrm{C}$ in a humidified atmosphere of $5 \%$ $\mathrm{CO}_{2}$.

Isolation of Primary Cultured Mouse Hepatocytes. Primary cultures of hepatocytes were isolated from female C57/BJ mice. After a midline incision, a sterile cannula was inserted through the right ventricle and preperfusion was performed at $37^{\circ} \mathrm{C}$ with preperfusion buffer $(0.5 \mathrm{mM}$ EGTA, $20 \mathrm{mM}$ Hepes in Hanks' balanced salt solution, $\mathrm{pH}$ 7.4) for 10 minutes. The preperfusion buffer was then replaced with perfusion buffer $\left(20 \mathrm{mM} \mathrm{NaHCO}{ }_{3}, 0.5 \mathrm{mg} / \mathrm{ml} \mathrm{BSA}\right.$, $6.7 \mathrm{mM} \mathrm{CaCl}_{2}, 100 \mathrm{U} / \mathrm{ml}$ type 2 collagenase, in Hanks' balanced salt solution, $\mathrm{pH}$ 7.4) for 7 minutes. The perfused liver was excised, rinsed in ice-cold William's medium E with $10 \% \mathrm{FCS}, 2 \mathrm{mM}$ L-glutamine, $2.5 \mathrm{mU} / \mathrm{ml}$ insulin, $1 \mu \mathrm{M}$ dexamethasone and gently disaggregated. After centrifugation, cells were counted, tested for viability, and cultured at $37^{\circ} \mathrm{C}$. After 3 hours of incubation, WME-a medium was replaced with WME-b medium (Williams medium E with $10 \%$ FCS, $2 \mathrm{mM}$ L-glutamine, $0.25 \mathrm{mU} / \mathrm{ml}$ insulin, $0.1 \mu \mathrm{M}$ dexamethasone). 
TABLE 1

Selected differentially expressed genes in liver from chow mice and high-fat diet (HFD) mice

Numbers in parentheses indicate gene expression levels quantified as log2 of fold changes.

Pathways Differentially Regulated in HFD Liver

Lipid metabolism

Gpat2 (0.7), Abhd4 (0.6), Acacb (1.2), Acsl5 (0.6), Acsm3 (1.0), Bche (0.7), Echs1 (0.5), Hadh (0.9), Acaca (0.7)

TGFb-induced EMT

TGFb2 (0.8), Jun (1.7), Fos (1.48), Fosl1 (0.8), Mmp2 (1.0), Edn1 (1.4), Vim (0.8), Ocln (-0.8)

Fatty acid metabolism

Cd74 (1.5), Elovl5 (1.6), Aacs (2.0), Acaa1b (1.3), Acacb (1.2), Acsf3 (0.7), Acsl5 (0.6), Acsm3 (1.0), Ch25h (1.3), Elovl2 (0.9), Echs1 (0.5), Fads1 (0.8),

Fads2 (1.3), Fasn (1.5), Gpam (0.9), Hao2 (3.0), Hadh (0.9), Hsd17b4 (0.5), Myo5a (1.0), Elovl6 (0.9), Acaca (0.7), Scd1 (1.6), Scd2 (1.0), Scd3 (1.5)

Arachidonic acid metabolism

Cbr3 (1.6), Pla2g6 (0.9), Cyp2c29 (-1.2), Сyp2c37 (-0.8), Сyp2c39 (-0.7), Сyp2c44 (-1.0), Сyp2c50 (-0.7), Сyp2c54 (-1.2), Cyp2c55 (-1.3),

Cyp2c70 (-1.6), Cyp4f14 (-0.7)

Isolation of Primary Cultured Human Hepatocytes. Primary human hepatocytes were prepared as previously described (Lee et al., 2014) and seeded in six-well plates in hepatocyte maintenance medium supplemented with UltraGlutamine for approximately 5 hours before further treatment procedures. Primary human hepatocytes were cultured at $37^{\circ} \mathrm{C}$ in a humidified atmosphere containing $5 \% \mathrm{CO}_{2}$.
Transient Transfection. Huh7 cells were transiently transfected with pCMV6-Cyp2c29 vector (MR20784, OriGENE). Cells were grown until $80 \%$ confluent in six-well plates and then transfected using Fugene HD (Promega Life Sciences, Madison, WI) transfection reagent and Opti-MEM (Gibco, Reinach, Switzerland) according to the manufacturer's protocol. Forty-eight hours after transfection, the cells were treated with the desired experimental conditions.
A

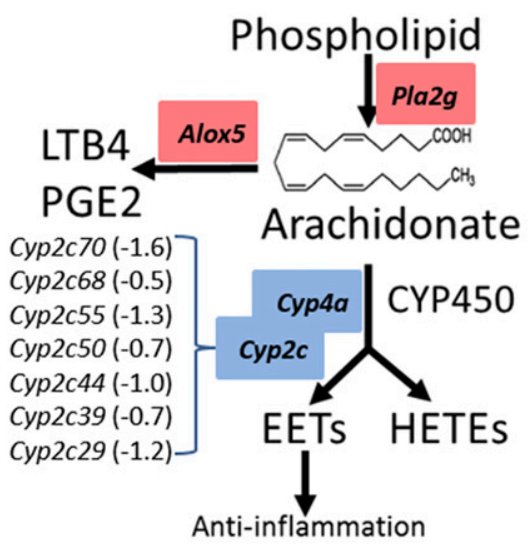

D

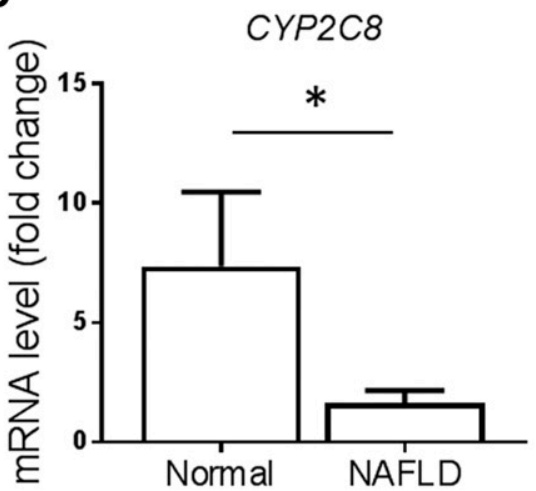

B
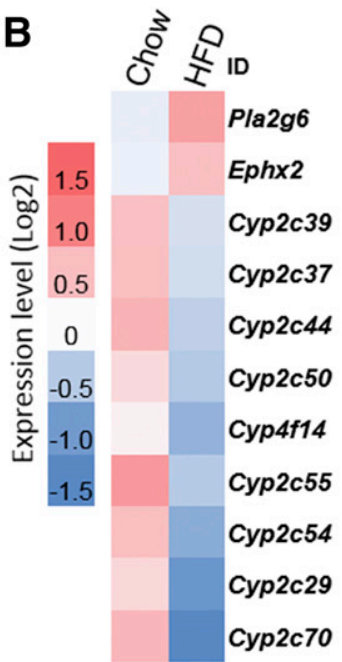

E

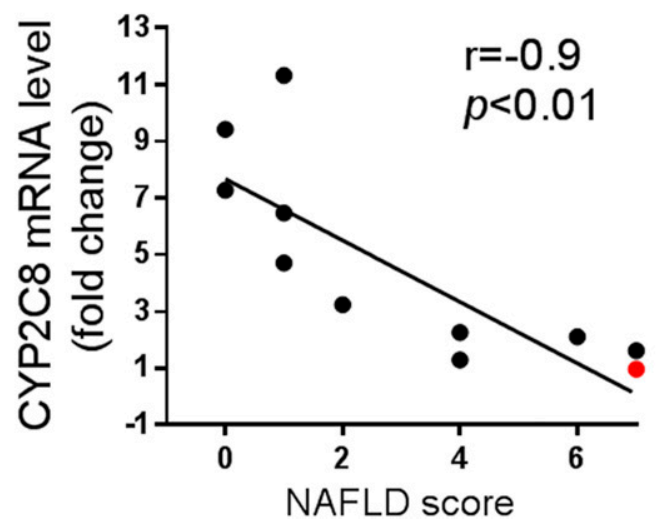

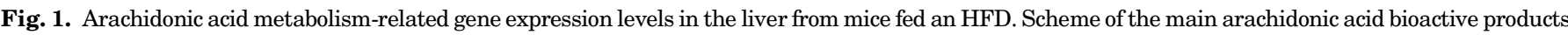

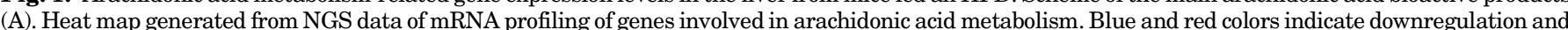

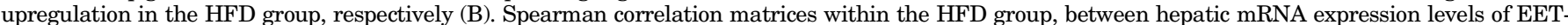

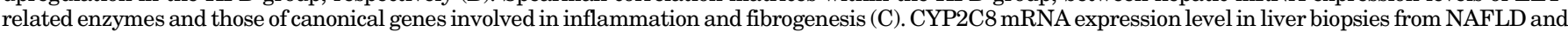

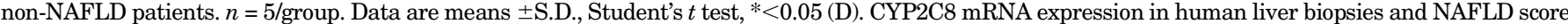
correlation, as determined by histology. Data were normalized for the lowest CYP2C8 mRNA expression value (shown in red) (E). 
A

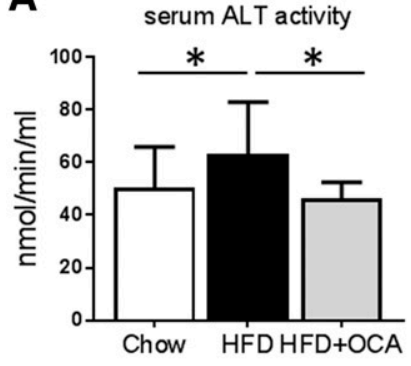

D

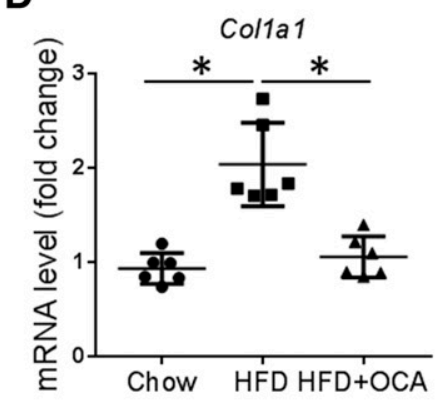

G

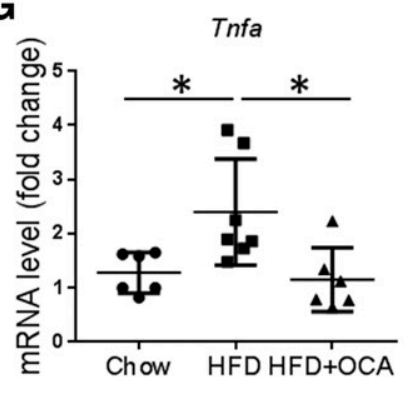

B

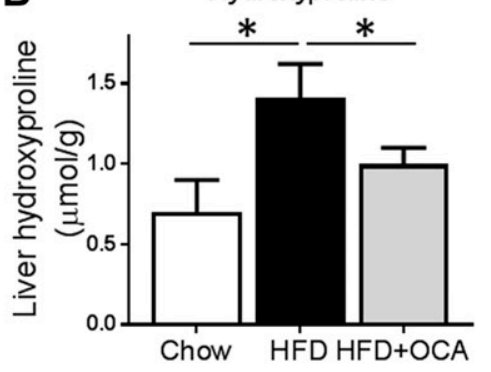

E

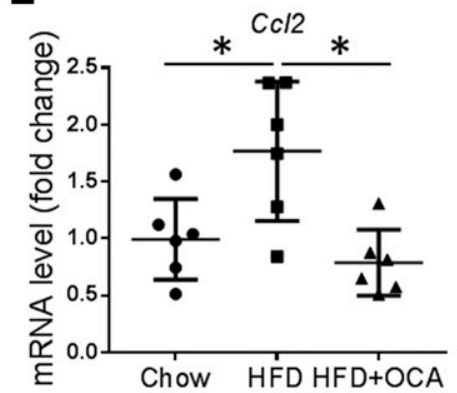

H

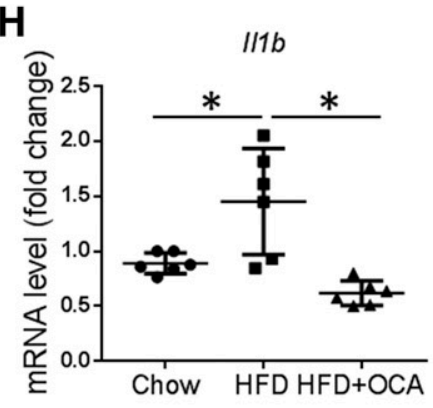

HFD

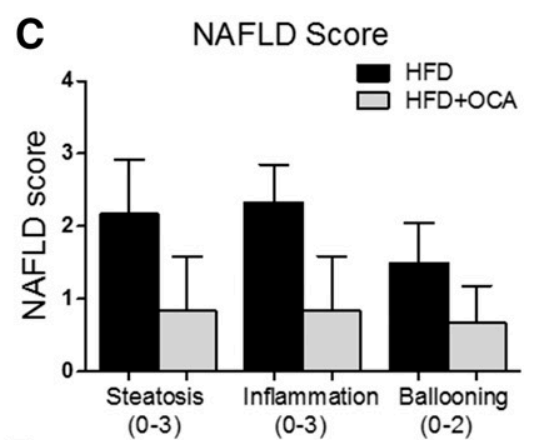

F
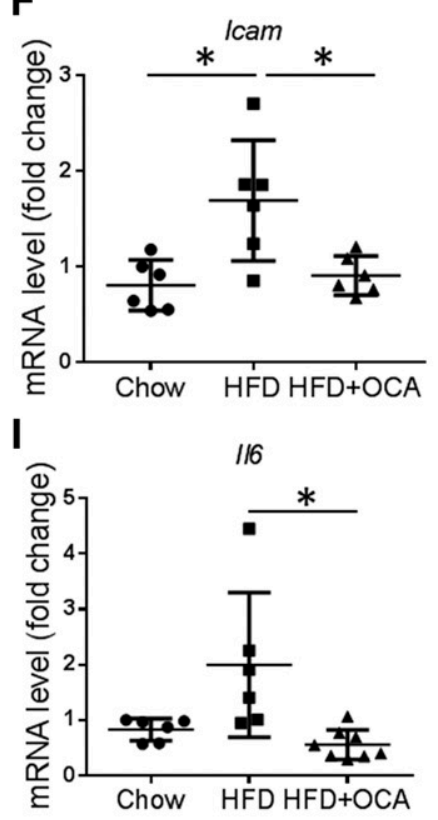

HFD+OCA

$\mathbf{J}$

Chow

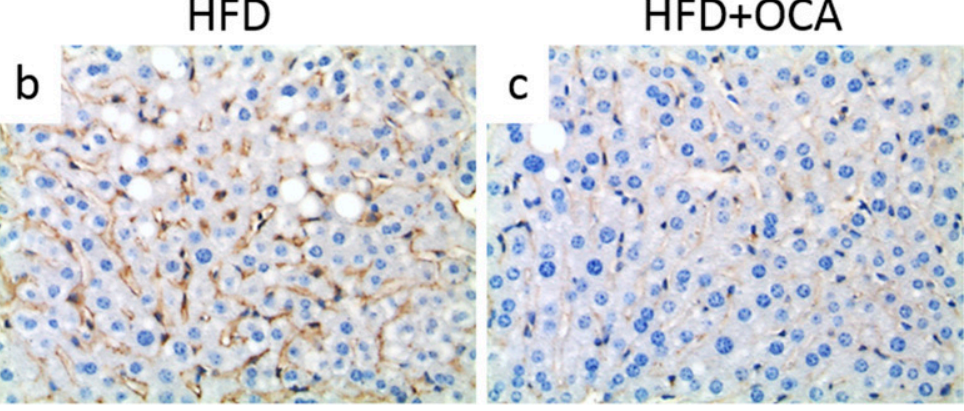

K

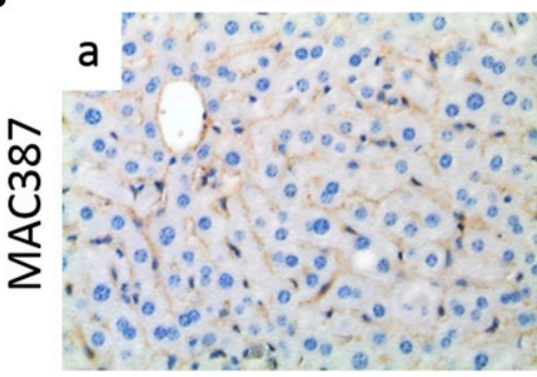

$\mathbf{a}$

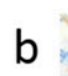

苟

C

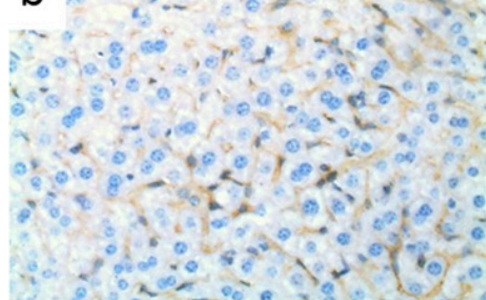

Fig. 2. Inhibitory effect of OCA on HFD-induced NASH. Serum ALT (A), serum hydroxyproline (B), hepatic NAFLD score (C). Hepatic mRNA levels of mCol1a1 (D), mCcl2 (E), mIcam (F), mTnfa (G), mIl1b (H) and mIl6 (I). $n \geq 6$ mice/group. Data are means \pm S.D., one-way ANOVA $<0.05$, Tukey's test, $*<0.05$. Representative images of immunostaining for the macrophage marker MAC387 (J) and CD4 (K) in liver sections from chow (a), HFD (b) and HFD +OCA (c) groups. 

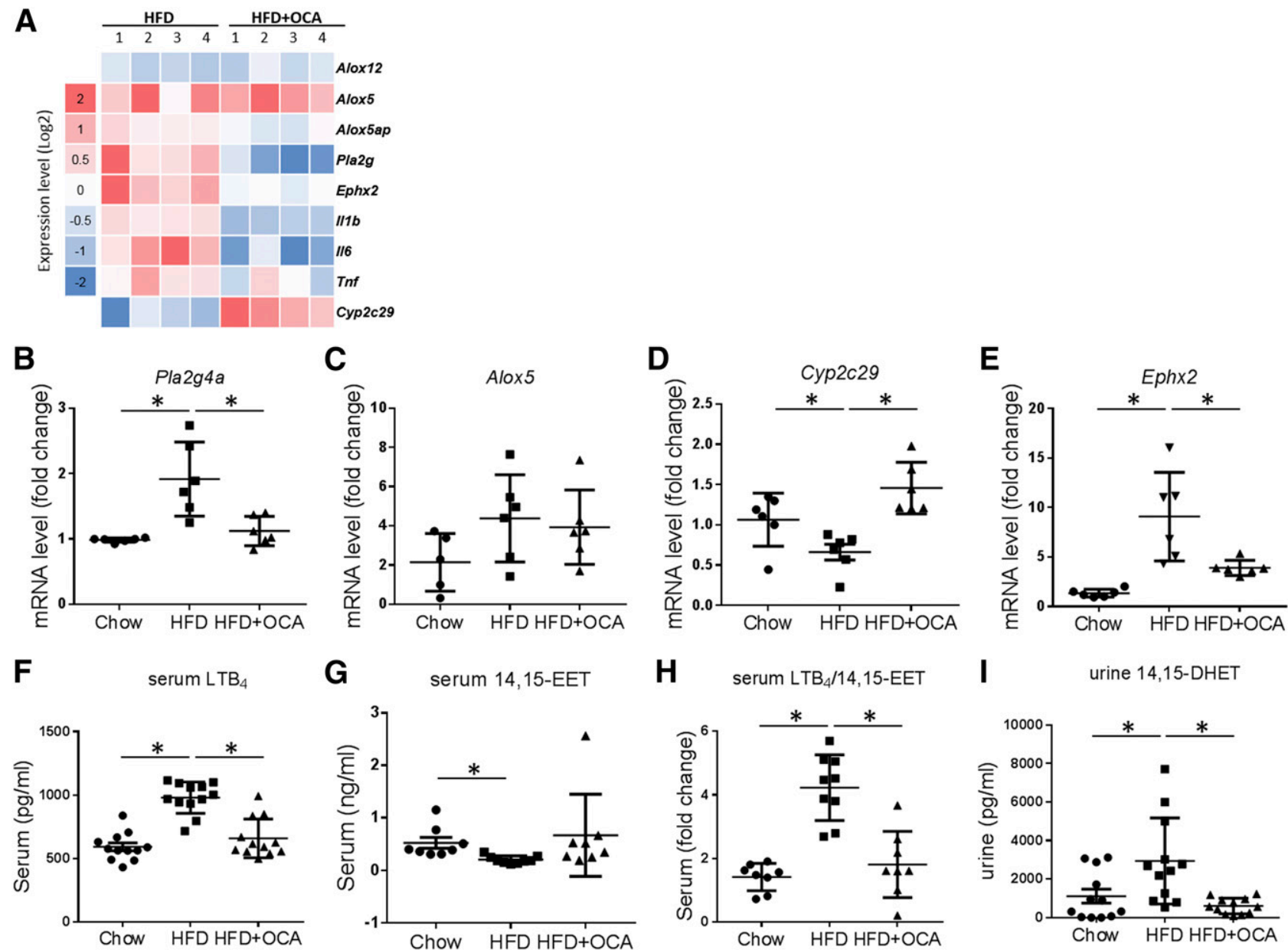

Fig. 3. Regulatory effect of OCA on arachidonic acid metabolism. Heat map of mRNA profiling of selected genes involved in arachidonic acid metabolism. The relative expression values of each target gene were measured in the chow, HFD, and HFD + OCA mice, normalized for the expression of $\beta$-actin and then expressed as HFD:chow (HFD) or HFD + OCA:chow (HFD + OCA) ratio. Each column represents an individual sample. Blue and red colors indicate downregulation and upregulation, respectively $(\mathrm{A})$. Relative hepatic mRNA levels of arachidonate partitioning genes $(\mathrm{B}-\mathrm{E})$. Serum levels of LTB $\mathrm{B}_{4}(\mathrm{~F})$ and 14,15-EET (G). Ratio between serum LTB 4 and serum 14,15-EET (H). Urinary levels of 14,15-DHET (I). Data are means \pm S.D., one-way ANOVA $<0.05$, Tukey's test, $*<0.05 . n \geq 6$ mice/group.

Migration Assay. Huh7 cells or primary cultured human hepatocytes were seeded on 12 -well plates at a density of $0.5 \times 10^{4}$ cells/well and then treated with the indicated conditions. After 48-72 hours, $3-\mu \mathrm{m}$ pore polycarbonate membrane inserts (Costar Corning, Darmstadt, Germany) were mounted on the wells, seeded with THP-1 cells, and incubated for 2 hours at $37^{\circ} \mathrm{C}$. The inserts were washed, fixed, and stained with crystal violet for analysis. The medium in which Huh7 cells were grown was collected for LTB 4 , EET, and DHET content assessment; total RNA was extracted from cells for real-time polymerase chain reaction analysis. For the migration assay with primary cultured mouse hepatocytes, J774 mouse cells were used as monocyte-like cells.

Statistics. Data are expressed as mean \pm S.D. For microarray data, comparison was assessed by student's $t$ test with R/ Bioconductor 3.6 (https://www.bioconductor.org/) to generate differentially expressed genes (chow vs. HFD). For other data relating to baseline characteristic analysis and histologic analysis, comparisons between groups were assessed by either student's $t$ test or one-way analysis of variance followed by Tukey's test. Statistical comparisons were performed using GraphPad Prism (version 5.0 for Windows; GraphPad Software, San Diego, CA).

Study Approval. All animal experiments and protocols conformed to the Swiss animal protection laws and were approved by the Cantonal Veterinary Office (study no. 2012058). The human study was conducted according to the Declaration of Helsinki guidelines regarding ethical principles for medical research involving human subjects. All patients provided written informed consent, and the study protocol was approved by the Scientific Ethical Committee of Peking University, Beijing, China, where patients were based (license no. PKU2010034). Primary human hepatocytes were isolated by Human Tissue and Cell Research Foundation upon written informed consent from the patient. The study was approved by the ethics committee of the medical faculty of the Ludwig Maximilian University (approval no. 025-12) in compliance with the Bavarian Data Protection Act.

\section{Results}

HFD-Induced Hepatic Inflammation Is Characterized by Decreased Expression of Cytochrome P450 Epoxygenases. Mice fed an HFD for 16 weeks displayed greater hepatic lipid deposition and fibrosis than did chow mice (Supplemental Fig. 1, A and B). An NAFLD activity score $\geq 5$ is consistent with a diagnosis of nonalcoholic steatohepatitis (NASH). The activity score from the liver of HFD mice was $\geq 5$ (Supplemental Fig. 1C). 
A
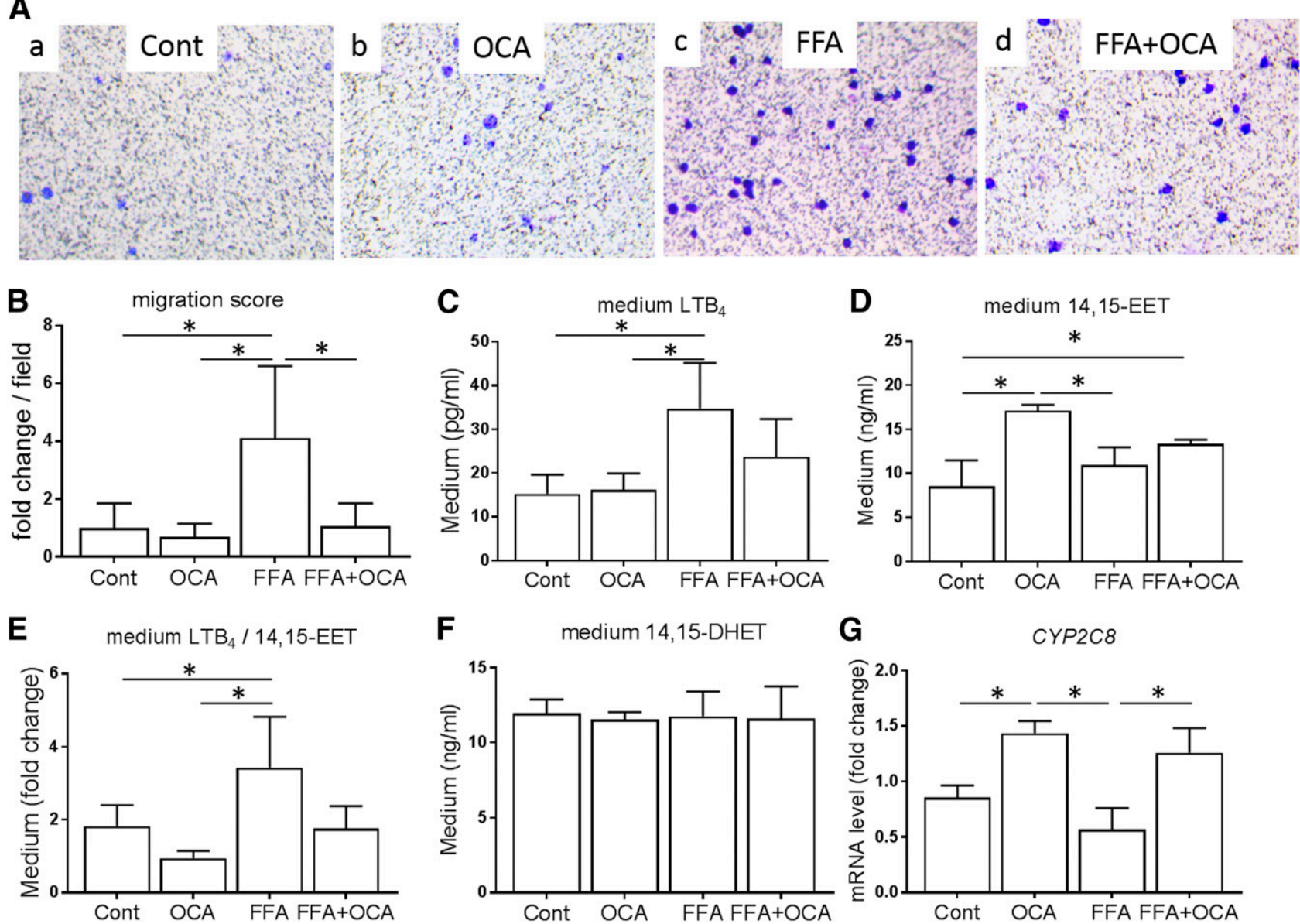

Fig. 4. Effect of FXR activation on arachidonate metabolism and FFA-induced monocyte migration. Representative images showing crystal violet staining of THP-1 cells onto a 3- $\mu \mathrm{m}$ pore polycarbonate membrane insert upon exposure to the medium of Huh7 cells treated with $50 \mu \mathrm{M}$ FFA in the presence or absence of $2 \mu \mathrm{M}$ OCA (a-d) (A). Relative migration score (B). Levels of $\mathrm{LTB}_{4}$ (C), 14,15-EET (D), LTB 4 /14,15-EET ratio (E), and 14,15-DHET (F) in the medium of Huh7 cells exposed to $50 \mu \mathrm{M}$ FFA in the presence or absence of $2 \mu \mathrm{M}$ OCA. mRNA levels of CYP2C 8 in Huh7 cells with the different treatments (G). Data are means \pm S.D., one-way ANOVA $<0.05$, Tukey's test, $*<0.05 . n=4$ /group.

The arachidonic acid metabolism pathway was markedly changed in the liver from mice fed an HFD (Table 1). The mRNA levels of cytosolic phospholipase A2 (Pla2g) and Alox5, the first committed steps in $\mathrm{LTB}_{4}$ synthesis pathway, were higher $(P<0.05)$ in the livers of HFD mice compared with that of chow mice (Fig. 1, A and B). Serum $\mathrm{LTB}_{4}$ was increased as well in the HFD group compared with the chow group (Supplemental Fig. 2A). Our data are consistent with a recent study demonstrating an increased hepatic expression of genes associated with eicosanoid synthesis in both diet- and genetic NAFLD mouse models (Hall et al., 2017). Hepatic EET synthesis and degradation in mammalian species are catalyzed mainly by CYP2C epoxygenases and epoxide hydrolase 2 (EPHX2), respectively (Spector and Norris, 2007). The expression of several Cyp2c genes was decreased $(P<0.05)$ in the livers of HFD mice compared with that of chow mice (Fig. 1, A and B; Table 1). In contrast, the mRNA level of Ephx2, which hydrolyzes EETs to the inactive dihydroxyeicosatrienoic acids (DHETs), was markedly higher than that in the liver of chow mice (Fig. 1B). The concomitant downregulation of several Cyp2c genes and upregulation of Ephx2 resulted in decreased serum 14,15-EET levels and increased urine 14,15DHET levels in the HFD group compared with the chow group (Supplemental Fig. 2, B and C). Overall, HFD mice were characterized by an imbalance of arachidonate metabolism toward inflammation. The expression of canonical genes involved in inflammation and fibrosis strongly correlated with that of EET-related genes in HFD mice (Fig. 1C). Notably, the mRNA level of CYP2C8, one of the major epoxygenases in human liver, was decreased as compared with that from nonNAFLD patients $(P<0.05)$ (Fig. 1D). A negative correlation between CYP2C8 mRNA levels and NAFLD score was observed (Fig. 1E). The present data suggest that the expression level of genes involved in EET metabolism, and, in turn, EET levels, might regulate the hepatic expression of inflammatory cytokines. Indeed, EET treatment could reduce the synthesis of proinflammatory cytokines (Li et al., 2015b).

Obeticholic Acid Induces CYP450 Epoxygenase Expression and Protects the Liver from Inflammation In Vivo. The impact of FXR activation on arachidonic acid metabolism and on the progression of HFD-induced hepatic inflammation was evaluated. The HFD + OCA group showed a reduction in: 1) hepatic lipid accumulation, 2) serum ALT levels, 3) inflammation, and 4) fibrosis compared with the HFD group (Fig. 2; Supplemental Fig. 3).

The arachidonate metabolism gene expression pattern was markedly changed by FXR activation (Fig. 3A). Alox5 was not affected by OCA treatment (Fig. 3C), but Cyp2c29, one of the 
A

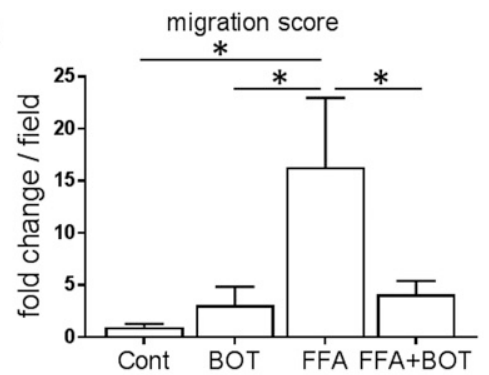

D

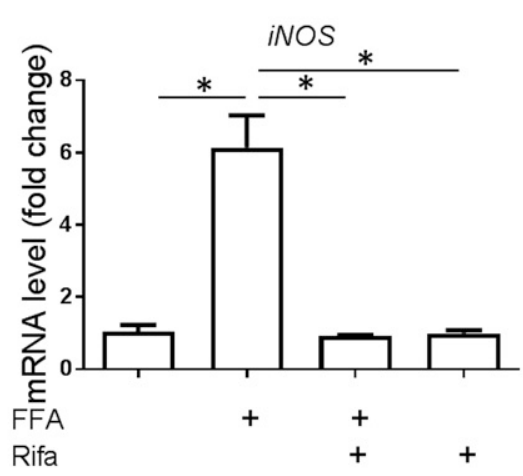

B

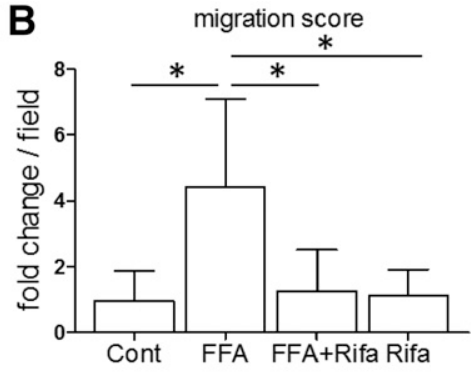

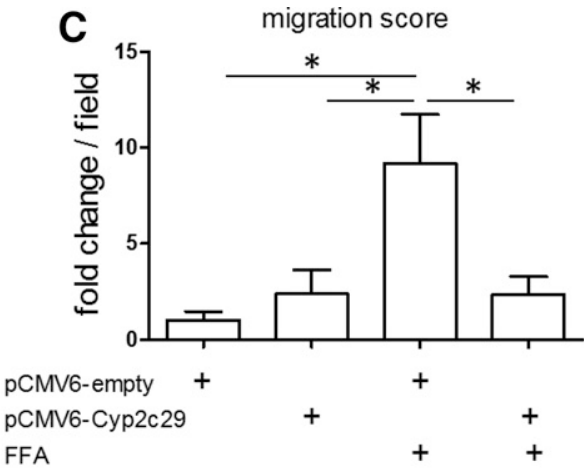

E
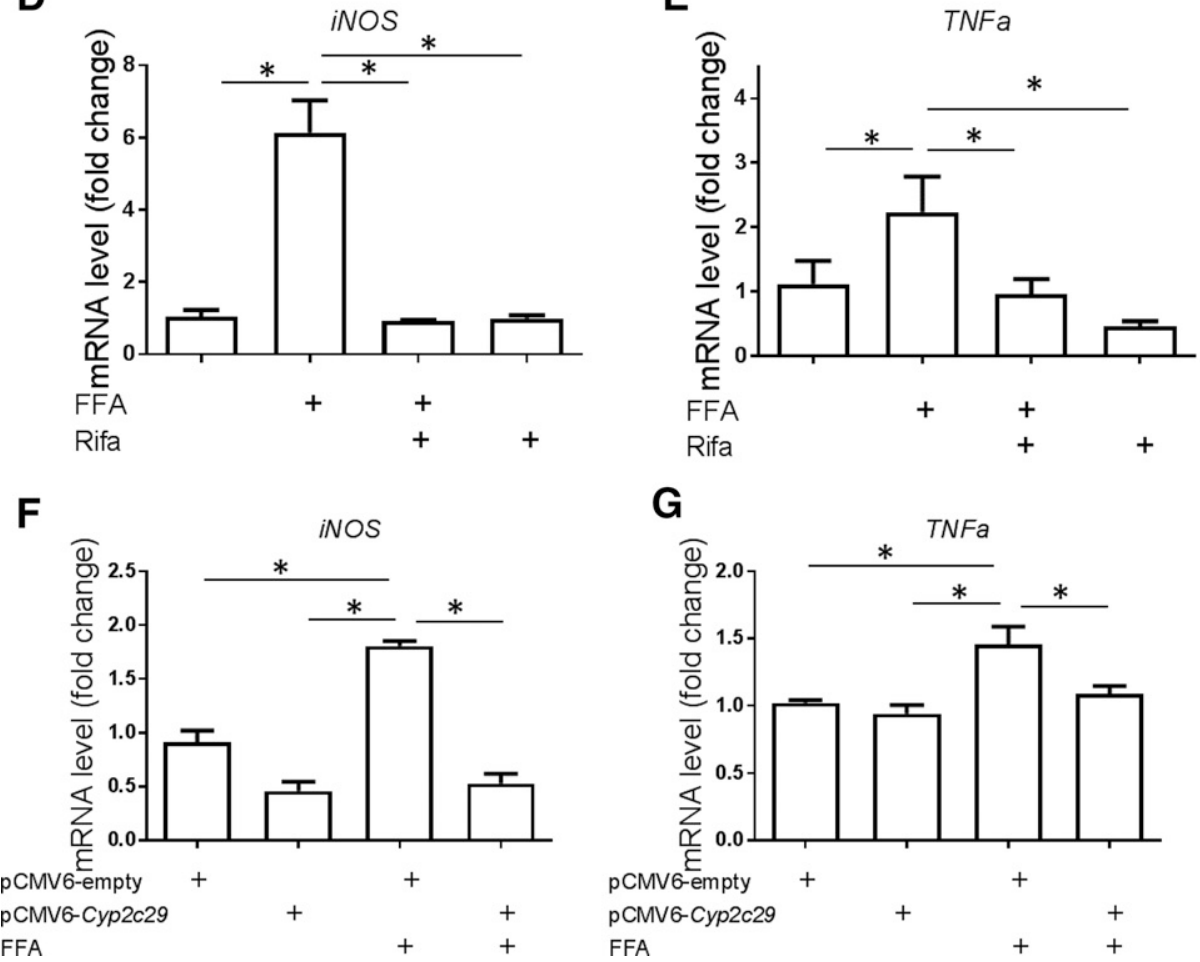

G

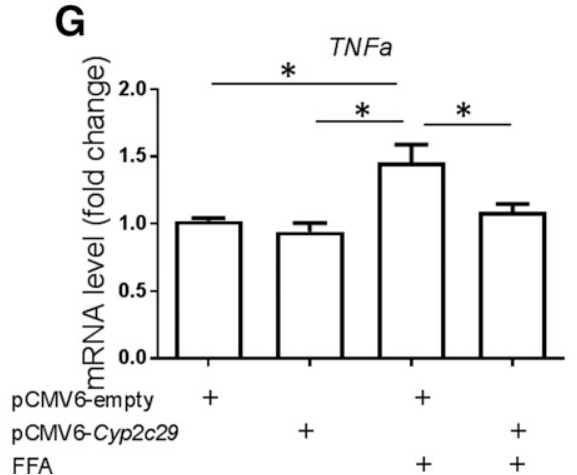

Fig. 5. Effect of NF-kB and CYP450 epoxygenase modulation on FFA-induced migration. Migration score of THP-1 cells in the medium of Huh7 cells treated with $50 \mu \mathrm{M}$ FFA in combination with $10 \mu \mathrm{M}$ NF-kB inhibitor benzoxathiole derivative (BOT) (A) or $20 \mu \mathrm{M}$ rifampicin (B). The effect of $50 \mu \mathrm{M}$ FFA on the migration of THP-1 cells in the medium of Huh7 cells transiently overexpressing Cyp2c29 (C). mRNA expression levels of NF-kB target genes in Huh7 cells exposed to $50 \mu \mathrm{M}$ FFA and $20 \mu \mathrm{M}$ rifampicin (D and E). The mRNA expression levels of NF-kB target genes in Huh7 cells transiently overexpressing cyp2c29 and exposed to $50 \mu \mathrm{M} \mathrm{FFA}(\mathrm{F}$ and G). Data represent the mean \pm S.D., one-way ANOVA $<0.05$, Tukey's test, $*<0.05 . n=3 /$ group.

main epoxygenases in mouse liver, was induced by OCA treatment $(P<0.05)$ (Fig. 3D). The mRNA levels of phospholipase $\mathrm{A} 2$ and $\mathrm{Ephx} 2$, induced by HFD, were restored to the levels of the chow mice by OCA $(P<0.05)$ (Fig. 3, B and E). Serum $\mathrm{LTB}_{4}$ levels were increased in HFD mice $(P<0.05)$ (Fig. 3F). Serum 14,15-EET levels were decreased in obese mice $(P<0.05)$ (Fig. 3G). Similarly, urine 14,15-DHET levels were increased in HFD mice $(P<0.05)$ (Fig. 3I). 14,15-EET and 14,15-DHET levels in the HFD + OCA group resembled those in the chow group, in line with the induction of several Cyp2c and the downregulation of Ephx2 mRNA levels. Overall, serum $\mathrm{LTB}_{4} / \mathrm{EET}$ index, increased by HFD, was lowered by OCA to the level of the chow mice $(P<0.05)$ (Fig. 3H). Overall, OCA could fine-tune arachidonic acid metabolism by reducing $\mathrm{LTB}_{4}$ levels and inducing EET levels.

FFA-Induced Monocyte Migration In Vitro Depends on P450 Epoxygenase Activity. To characterize the interaction between CYP450 epoxygenase and OCA, migration assays were performed in vitro. OCA at an extracellular concentration of $2 \mu \mathrm{M}$ activated FXR in Huh7 cells (Supplemental Fig. 4). The migration induced by FFA was completely abolished by coincubation with OCA $(P<0.05)$ (Fig. 4 , A and B). FFA-induced migration was associated with higher $\mathrm{LTB}_{4}$ levels in the culture medium compared with that from the untreated cells and those coexposed to FFA and OCA $(P<0.05)$ (Fig. 4C). Interestingly, 14,15 EET levels were not affected by FFA treatment, but Huh7 cells exposed to OCA showed higher levels of 14,15-EETs in the medium $(P<0.05)$ (Fig. 4D). Overall, the ratio of $\mathrm{LTB}_{4} / 14,15$-EETs was markedly decreased in the medium of cells cotreated with FFA and OCA compared with that in FFA-treated cells $(P<0.05)$ (Fig. 4E). 14,15-DHET levels in the culture medium were not changed among the different treatments (Fig. $4 \mathrm{~F}$ ), indicating the changes of 14,15 EET levels were not due to an increased degradation via EPHX2. Along with this, the mRNA level of CYP2C8, one of the main CYP450 epoxygenases in human 
A
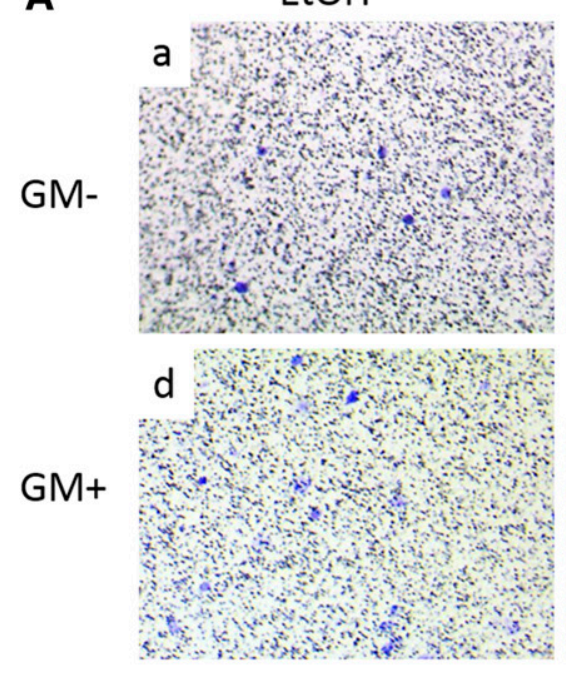

B

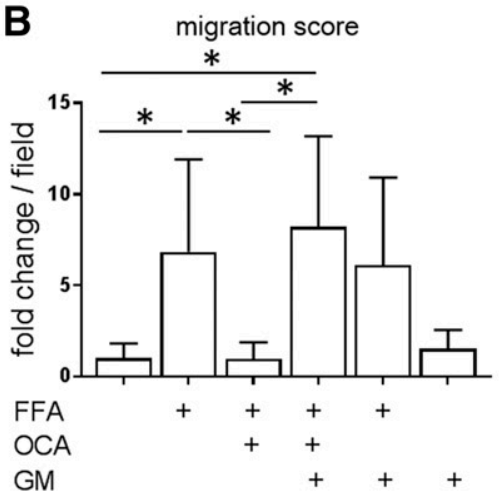

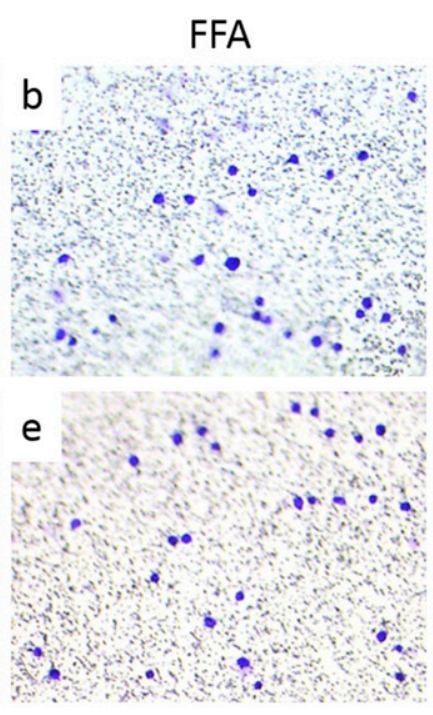

C

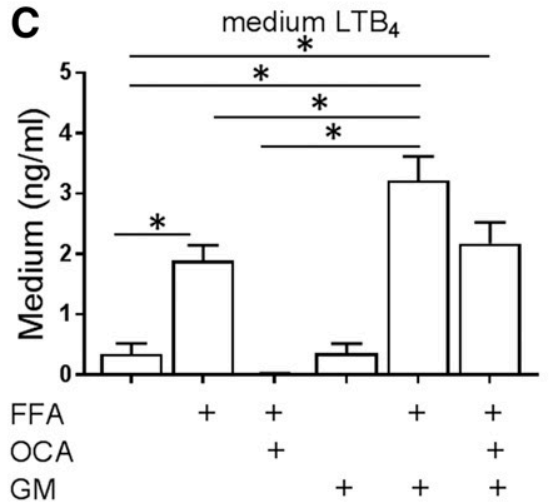

FFA+OCA
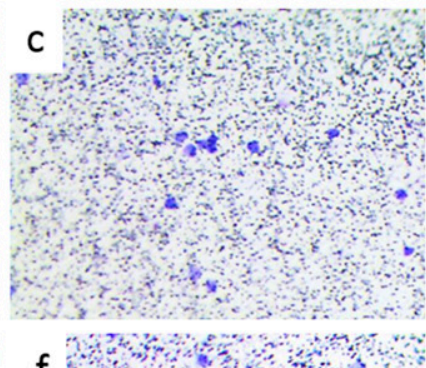
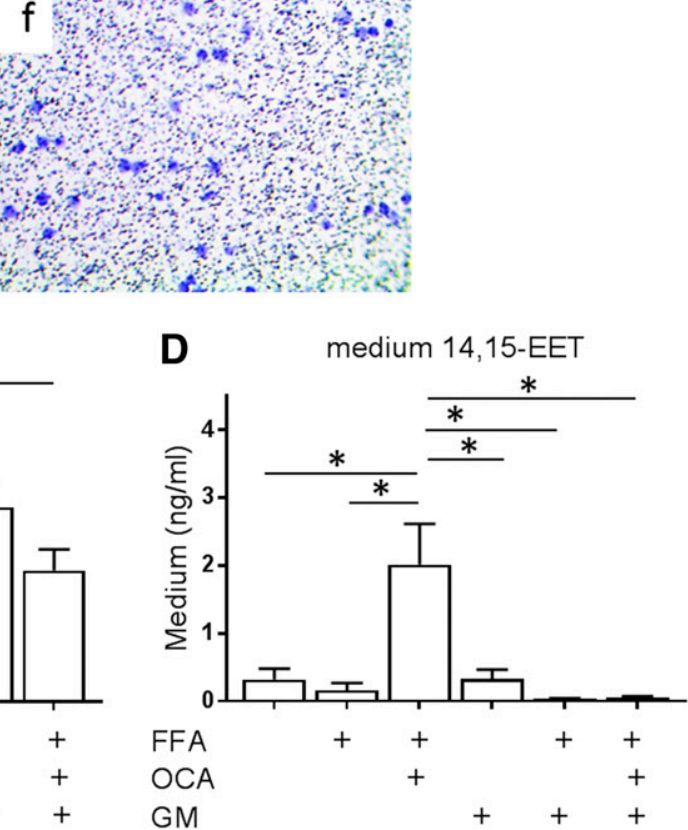

Fig. 6. Effect of gemfibrozil on OCA-mediated anti-inflammatory action. Representative images showing crystal-violet staining of THP-1 cells onto a $3-\mu \mathrm{m}$ pore polycarbonate membrane insert upon exposure to the medium of Huh7 cells treated with $50 \mu \mathrm{M}$ FFA in the presence or absence of $2 \mu \mathrm{M}$ of OCA and $100 \mu \mathrm{M}$ of GM (a-f) (A). Relative migration score (B). Levels of LTB 4 (C), 14,15-EET (D) in the medium of Huh7 cells exposed to $50 \mu \mathrm{M}$ FFA in the presence or absence of $2 \mu \mathrm{M}$ OCA and $100 \mu \mathrm{M} \mathrm{GM}) . * 0.05$.

liver, was induced by OCA treatment $(P<0.05)$ (Fig. 4G). Similar results were obtained using primary cultured hepatocytes from mice (Supplemental Fig. 5, A and B) and humans (Supplemental Fig. 5, C and D). The protective effect of OCA was fully abolished by the coincubation with z-guggulsterone, an FXR antagonist, ruling out any potential off-target effect of OCA on hepatocytes (Supplemental Fig. 6). The lack of protection by OCA when THP-1 cells were exposed to exogenous $\mathrm{LTB}_{4}$ indicates that OCA inhibited migration by modulating the synthesis of eicosanoids and not by altering the downstream signaling pathway (Supplemental Fig. 7).

When Huh7 cells were coincubated with FFA and benzoxathiole derivative, an NF- $\kappa \mathrm{B}$ inhibitor (Kim et al., 2008), FFA-induced THP-1 migration was completely abolished, suggesting that FFA-induced inflammation was NF- $\kappa \mathrm{B}$ dependent (Fig. 5A). EETs can suppress NF- $\kappa$ B signaling as well (Dai et al., 2015). In fact, induction of CYP2C gene expression levels in Huh7 cells by pretreatment with rifampicin, an FXRindependent pan-inducer of CYP2C epoxygenases (Raucy et al., 2002), or by transfection of Cyp2c29 abolished FFA-induced THP-1 cell migration (Fig. 5, B and C) as well as FFA-induced NF- $\kappa$ B signaling (Fig. 5, D-G).

It is possible that the inhibitory effect of FXR activation on $\mathrm{NF}-\kappa \mathrm{B}$-induced inflammation is EET-dependent. To address this issue, Huh7 cells were coincubated with FFA, OCA, and gemfibrozil (GM), a pan-inhibitor of CYP2C activity (Wen et al., 2001; Shitara et al., 2004). GM abolished the effect of OCA on arachidonate metabolite synthesis and on THP-1 migration induced by FFA (Fig. 6). Overall, these results indicate that the inhibitory effects of FXR activation on NF- $\kappa \mathrm{B}$ signaling was EET-dependent.

\section{Discussion}

In the present study, mice fed an HFD displayed an inflammatory and fibrotic pattern compatible with NASH that strongly correlated with a switch in the expression pattern of arachidonate-partitioning genes, notably the downregulation of a number of Cyp2c enzymes that epoxygenate arachidonic acid to EETs, and upregulation of the Ephx2, which inactivates EETs to DHETs (Chacos et al., 1983; Capdevila et al., 1990). As a result, mice fed an HFD were characterized by a dramatic increase in the $\mathrm{LTB}_{4} / \mathrm{EET}$ ratio. Arachidonic acid breakdown and $\mathrm{LTB}_{4}$ formation are known to drive hepatic inflammation (Martínez-Clemente et al., 2010). The present data suggest that EETs are also important in the inflammatory process and may serve as a quencher of $\mathrm{LTB}_{4}$ signal, buffering the inflammation. The reduced quenching capacity of mice fed an HFD is likely to 

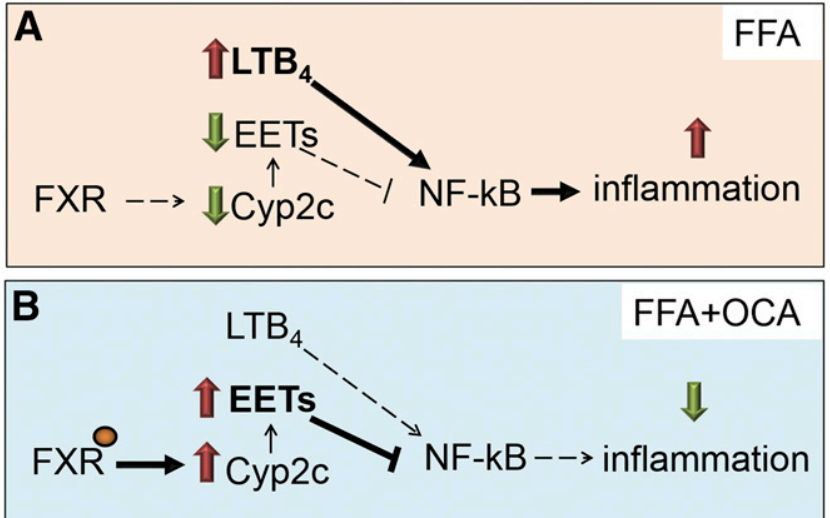

Fig. 7. Model of the FXR-mediated repression of NF- $\kappa$ B signaling. Increased $\mathrm{LTB}_{4}$ levels and decreased and EET levels promote NF- $\kappa \mathrm{B}$ signaling, which triggers hepatic inflammation (A). Transactivation of P450 epoxygenase expression and EET synthesis by FXR, which, in turn, inhibits the NF- $\kappa$ B signaling (B).

"unleash" the inflammatory signal produced by the resident macrophages.

OCA treatment elicited less hepatic steatosis, lower expression of proinflammatory cytokines, and less macrophage infiltration. OCA treatment reprogrammed arachidonate metabolism by inducing P450 epoxygenase expression and downregulating phospholipase A2. These adjustments channeled arachidonic acid into EET synthesis. By boosting EET synthesis, OCA increased the buffering capacity of the liver and antagonized the inflammatory process. Furthermore, mice fed an HFD and treated with OCA showed a reduced expression of Ephx2, which further contributed to sustain higher levels of EETs. The anti-inflammatory effect of OCA in vitro was fully abolished by coincubation with the FXR inhibitor z-guggulsterone, suggesting that OCA regulated the arachidonic acid pathway via FXR activation with no off-target effects (e.g., TGR5 activation). As FXR activation was reported to modulate macrophage activity, resident macrophages may also respond to the treatment with OCA and contribute to anti-inflammatory effect (McMahan et al., 2013; Verbeke et al., 2016).

Independent studies have shown that both EETs and FXR inhibit the NF-kB pathway (Carroll et al., 2006; Yang et al., 2007; Xu et al., 2010); however when the P450 epoxygenase activity was inhibited, OCA could not inhibit NF-kB signaling, suggesting that CYP450 epoxygenase activity is a precondition for FXR-mediated repression of NF-kB signaling (Fig. 7).

To conclude, the induction of $\mathrm{P} 450$ epoxygenase expression and EET levels is a novel feature of FXR activation and is required for the FXR-mediated NF-kB signaling repression. EET analogs have been reported to attenuate adipogenesis, insulin resistance, and inflammation in the adipose tissue of obese mice (Spite et al., 2011; Sodhi et al., 2012; Zha et al., 2014; Li et al., 2015b). Thus, restoring the proper levels of EETs is likely to be beneficial in NAFLD management as well. The induction of endogenous EET levels may contribute to the protective effect of obeticholic acid observed in NAFLD in the clinical setting.

\section{Authorship Contributions}

Participated in research design: Gai, Visentin, Kullak-Ublick.
Conducted experiments: Gai, Visentin, Gui, Zhao, Thasler, Häusler, Hartling, Cremonesi, Hiller.

Performed data analysis: Gai, Visentin, Gui, Zhao, Hartling, Cremonesi.

Wrote or contributed to the writing of the manuscript: Gai, Visentin, Hartling, Kullak-Ublick.

\section{References}

Bettaieb A, Nagata N, AbouBechara D, Chahed S, Morisseau C, Hammock BD, and Haj FG (2013) Soluble epoxide hydrolase deficiency or inhibition attenuates diet-induced endoplasmic reticulum stress in liver and adipose tissue. J Biol Chem 288:14189-14199.

Capdevila JH, Falck JR, Dishman E, and Karara A (1990) Cytochrome P-450 arachidonate oxygenase. Methods Enzymol 187:385-394.

Carroll MA, Doumad AB, Li J, Cheng MK, Falck JR, and McGiff JC (2006) Adenosine2A receptor vasodilation of rat preglomerular microvessels is mediated by EETs that activate the cAMP/PKA pathway. Am J Physiol Renal Physiol 291: F155-F161.

Chacos N, Capdevila J, Falck JR, Manna S, Martin-Wixtrom C, Gill SS, Hammock $\mathrm{BD}$, and Estabrook RW (1983) The reaction of arachidonic acid epoxides (epoxyeicosatrienoic acids) with a cytosolic epoxide hydrolase. Arch Biochem Biophys 223:639-648.

Chou RC, Kim ND, Sadik CD, Seung E, Lan Y, Byrne MH, Haribabu B, Iwakura Y, and Luster AD (2010) Lipid-cytokine-chemokine cascade drives neutrophil recruitment in a murine model of inflammatory arthritis. Immunity 33:266-278.

Dai M, Wu L, He Z, Zhang S, Chen C, Xu X, Wang P, Gruzdev A, Zeldin DC, and Wang DW (2015) Epoxyeicosatrienoic acids regulate macrophage polarization and prevent LPS-induced cardiac dysfunction. J Cell Physiol 230:2108-2119.

Deng Y, Theken KN, and Lee CR (2010) Cytochrome P450 epoxygenases, soluble epoxide hydrolase, and the regulation of cardiovascular inflammation. J Mol Cell Cardiol 48:331-341.

Fisher CD, Lickteig AJ, Augustine LM, Ranger-Moore J, Jackson JP, Ferguson SS, and Cherrington NJ (2009) Hepatic cytochrome P450 enzyme alterations in humans with progressive stages of nonalcoholic fatty liver disease. Drug Metab Dispos 37:2087-2094.

Gai Z, Gui T, Hiller C, and Kullak-Ublick GA (2016) Farnesoid X receptor protects against kidney injury in uninephrectomized obese mice. $J$ Biol Chem 291: $2397-2411$

Hall Z, Bond NJ, Ashmore T, Sanders F, Ament Z, Wang X, Murray AJ, Bellafante E, Virtue S, Vidal-Puig A, et al. (2017) Lipid zonation and phospholipid remodeling in nonalcoholic fatty liver disease. Hepatology 65:1165-1180.

Hu Z, Ren L, Wang C, Liu B, and Song G (2012) Effect of chenodeoxycholic acid on fibrosis, inflammation and oxidative stress in kidney in high-fructose-fed Wistar rats. Kidney Blood Press Res 36:85-97.

Imig JD (2012) Epoxides and soluble epoxide hydrolase in cardiovascular physiology. Physiol Rev 92:101-130.

Jiang T, Wang XX, Scherzer P, Wilson P, Tallman J, Takahashi H, Li J, Iwahashi M, Sutherland E, Arend L, et al. (2007) Farnesoid X receptor modulates renal lipid metabolism, fibrosis, and diabetic nephropathy. Diabetes 56:2485-2493.

Kim BH, Roh E, Lee HY, Lee IJ, Ahn B, Jung SH, Lee H, Han SB, and Kim Y (2008) Benzoxathiole derivative blocks lipopolysaccharide-induced nuclear factor-kappaB activation and nuclear factor-kappaB-regulated gene transcription through inactivating inhibitory kappaB kinase beta. Mol Pharmacol 73:1309-1318.

Lee SM, Schelcher C, Laubender RP, Fröse N, Thasler RM, Schiergens TS, Mansmann U, and Thasler WE (2014) An algorithm that predicts the viability and the yield of human hepatocytes isolated from remnant liver pieces obtained from liver resections. PLoS One 9:e107567.

Li P, Oh DY, Bandyopadhyay G, Lagakos WS, Talukdar S, Osborn O, Johnson A, Chung H, Maris M, Ofrecio JM, et al. (2015a) LTB4 promotes insulin resistance in obese mice by acting on macrophages, hepatocytes and myocytes. Nat Med 21: 239-247.

Li R, Xu X, Chen C, Wang Y, Gruzdev A, Zeldin DC, and Wang DW (2015b) CYP2J2 attenuates metabolic dysfunction in diabetic mice by reducing hepatic inflammation via the PPAR $\gamma$. Am J Physiol Endocrinol Metab 308:E270-E282.

Luria A, Bettaieb A, Xi Y, Shieh GJ, Liu HC, Inoue H, Tsai HJ, Imig JD, Haj FG, and Hammock BD (2011) Soluble epoxide hydrolase deficiency alters pancreatic islet size and improves glucose homeostasis in a model of insulin resistance. Proc Natl Acad Sci USA 108:9038-9043.

Martínez-Clemente M, Ferré N, González-Périz A, López-Parra M, Horrillo R, Titos E, Morán-Salvador E, Miquel R, Arroyo V, Funk CD, et al. (2010) 5lipoxygenase deficiency reduces hepatic inflammation and tumor necrosis factor alpha-induced hepatocyte damage in hyperlipidemia-prone ApoE-null mice. Hepatology 51:817-827.

McMahan RH, Wang XX, Cheng LL, Krisko T, Smith M, El Kasmi K, Pruzanski M, Adorini L, Golden-Mason L, Levi M, et al. (2013) Bile acid receptor activation modulates hepatic monocyte activity and improves nonalcoholic fatty liver disease. $J$ Biol Chem 288:11761-11770.

Miyazaki-Anzai S, Levi M, Kratzer A, Ting TC, Lewis LB, and Miyazaki M (2010) Farnesoid X receptor activation prevents the development of vascular calcification in ApoE-/- mice with chronic kidney disease. Circ Res 106:1807-1817.

Needleman P, Turk J, Jakschik BA, Morrison AR, and Lefkowith JB (1986) Arachidonic acid metabolism. Annu Rev Biochem 55:69-102.

Raucy JL, Mueller L, Duan K, Allen SW, Strom S, and Lasker JM (2002) Expression and induction of CYP2C P450 enzymes in primary cultures of human hepatocytes. J Pharmacol Exp Ther 302:475-482.

Samuelsson B, Dahlén SE, Lindgren JA, Rouzer CA, and Serhan CN (1987) Leukotrienes and lipoxins: structures, biosynthesis, and biological effects. Science 237: 1171-1176. 
Shitara Y, Hirano M, Sato H, and Sugiyama Y (2004) Gemfibrozil and its glucuronide inhibit the organic anion transporting polypeptide 2 (OATP2/OATP1B1:SLC21A6) mediated hepatic uptake and CYP2C8-mediated metabolism of cerivastatin analysis of the mechanism of the clinically relevant drug-drug interaction between cerivastatin and gemfibrozil. J Pharmacol Exp Ther 311:228-236.

Sinal CJ, Tohkin M, Miyata M, Ward JM, Lambert G, and Gonzalez FJ (2000) Targeted disruption of the nuclear receptor FXR/BAR impairs bile acid and lipid homeostasis. Cell 102:731-744.

Sodhi K, Puri N, Inoue K, Falck JR, Schwartzman ML, and Abraham NG (2012) EET agonist prevents adiposity and vascular dysfunction in rats fed a high fat diet via a decrease in Bach 1 and an increase in HO-1 levels. Prostaglandins Other Lipid Mediat 98:133-142.

Spector AA and Norris AW (2007) Action of epoxyeicosatrienoic acids on cellular function. Am J Physiol Cell Physiol 292:C996-C1012.

Spite M, Hellmann J, Tang Y, Mathis SP, Kosuri M, Bhatnagar A, Jala VR, and Haribabu B (2011) Deficiency of the leukotriene B4 receptor, BLT-1, protects against systemic insulin resistance in diet-induced obesity. $J$ Immunol 187: $1942-1949$

Subbarao K, Jala VR, Mathis S, Suttles J, Zacharias W, Ahamed J, Ali H, Tseng MT, and Haribabu B (2004) Role of leukotriene B4 receptors in the development of atherosclerosis: potential mechanisms. Arterioscler Thromb Vasc Biol 24:369-375.

Tager AM and Luster AD (2003) BLT1 and BLT2: the leukotriene B(4) receptors. Prostaglandins Leukot Essent Fatty Acids 69:123-134.

Verbeke L, Mannaerts I, Schierwagen R, Govaere O, Klein S, Vander Elst I, Windmolders P, Farre R, Wenes M, Mazzone M, et al. (2016) FXR agonist obeticholic acid reduces hepatic inflammation and fibrosis in a rat model of toxic cirrhosis. Sci Rep 6:33453.
Weiss GA, Troxler H, Klinke G, Rogler D, Braegger C, and Hersberger M (2013) High levels of anti-inflammatory and pro-resolving lipid mediators lipoxins and resolvins and declining docosahexaenoic acid levels in human milk during the first month of lactation. Lipids Health Dis 12:89.

Wen X, Wang JS, Backman JT, Kivistö KT, and Neuvonen PJ (2001) Gemfibrozil is a potent inhibitor of human cytochrome P450 2C9. Drug Metab Dispos 29:1359-1361.

Xu X, Zhao CX, Wang L, Tu L, Fang X, Zheng C, Edin ML, Zeldin DC, and Wang DW (2010) Increased CYP2J3 expression reduces insulin resistance in fructose-treated rats and db/db mice. Diabetes 59:997-1005.

Yang S, Lin L, Chen JX, Lee CR, Seubert JM, Wang Y, Wang H, Chao ZR, Tao DD, Gong JP, et al. (2007) Cytochrome P-450 epoxygenases protect endothelial cells from apoptosis induced by tumor necrosis factor-alpha via MAPK and PI3K/Akt signaling pathways. Am J Physiol Heart Circ Physiol 293:H142-H151.

Zeldin DC (2001) Epoxygenase pathways of arachidonic acid metabolism. J Biol Chem 276:36059-36062

Zha W, Edin ML, Vendrov KC, Schuck RN, Lih FB, Jat JL, Bradbury JA, DeGraff LM, Hua K, Tomer KB, et al. (2014) Functional characterization of cytochrome P450-derived epoxyeicosatrienoic acids in adipogenesis and obesity. J Lipid Res 55:2124-2136.

Zhang S, Wang J, Liu Q, and Harnish DC (2009) Farnesoid X receptor agonist WAY362450 attenuates liver inflammation and fibrosis in murine model of non-alcoholic steatohepatitis. J Hepatol 51:380-388.

Address correspondence to: Dr. Gerd A. Kullak-Ublick, Department of Clinical Pharmacology and Toxicology, University Hospital Zurich, Rämistrasse 100, CH-8091 Zurich, Switzerland. E-mail: gerd.kullak@usz.ch 